\title{
EDITORIAL
}

\section{Ten principles for clean air}

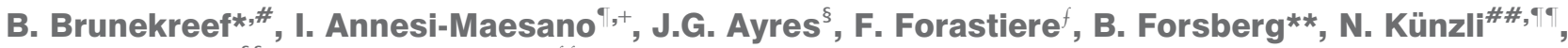 \\ J. Pekkanen ${ }^{+, \S \S}$ and T. Sigsgaard ${ }^{f f}$
}

$\mathbf{T}$ he European "Year of the Air" 2013 will be upon us soon: over the next several months, the European Union (EU) will revise its main air pollution control policies. Lack of clean air is one of the most important environmental threats to public health in Europe today. The European Respiratory Society Environment and Health Committee (www.ersnet.org) has developed 10 concise principles for clean air, which summarise the scientific state of the art and provide guidance for public health policy. This editorial was written in order to explain these 10 principles.

\section{1) Citizens are entitled to clean air, just like clean water and safe food.}

This principle, really, should be self-evident to the extent that one should be embarrassed to even mention it. But the reality is that millions of Europeans live in areas where it is unsafe to breathe the air around them.

The most recent EU key directive on ambient air quality is Directive 2008/50/EC. It recognises the need to reduce pollution to levels which minimise harmful effects on human health. The limit values adopted for airborne particulate matter were, however, far higher than recommended by the World Health Organization (WHO). For example, an annual average limit value for respirable particles (particulate matter with a $50 \%$ cut-off aerodynamic diameter of $2.5 \mu \mathrm{m}$; PM2.5) was set at $25 \mu \mathrm{g} \cdot \mathrm{m}^{-3}$ which is 2.5 times higher than the level recommended by the WHO. WHO guidelines are based on health considerations only, and do not take into account the economical or technical feasibility of meeting the guidelines. The EU Directive recognises that there is no identifiable threshold for PM2.5 and states that policies should aim at general reductions in concentrations at urban background sites. However, no binding legislative measures have been taken so far to enforce this. A detailed assessment of the public health aspects of the current directive has been published [1].

\footnotetext{
${ }^{*}$ Institute for Risk Assessment Sciences, Universiteit Utrecht, and ${ }^{*}$ Julius Center for Health Sciences and Primary Care, University Medical Center Utrecht, Utrecht, The Netherlands. "INSERM, U 707, EPAR, and +Université Pierre et Marie Curie - Paris 6, UMR S 707, EPAR, Paris, France. ${ }^{\S}$ Institute of Occupational and Environmental Medicine, University of Birmingham, Birmingham, UK ${ }^{f}$ Dipartimento di epidemiologia, Servizio sanitario regionale, Lazio, Italy. **Dept of Public Health and Clinical Medicine, Occupational and Environmental Medicine, Umeå University, Umeå, Sweden. \#\# Swiss Tropical and Public Health Institute, and "University of Basel, Basel, Switzerland. ${ }^{+ \text {Dept }}$ of Environmental Health, National Institute for Health and Welfare, and ${ }^{\S \S}$ Public Health and Clinical Nutrition, University of Eastern Finland, Kuopio, Finland. ${ }^{f f}$ Dept of Environmental and Occupational Medicine, School of Public Health, Aarhus University, Aarhus, Denmark.
}

CORRESPONDENCE: B. Brunekreef, Institute for Risk Assessment Sciences, Universiteit Utrecht, PO Box 80178, 3508 TD, Utrecht, The Netherlands. E-mail: B.Brunekreef@uu.nl
The EU target value for ozone is $120 \mu \mathrm{g} \cdot \mathrm{m}^{-3}$ as a maximum $8-\mathrm{h}$ average value, not to be exceeded on more than 25 days a year. The WHO air quality guideline is $100 \mu \mathrm{g} \cdot \mathrm{m}^{-3}$, and even at this level WHO estimates a $1-2 \%$ increase in daily mortality compared to a baseline of $70 \mu \mathrm{g} \cdot \mathrm{m}^{-3}$.

Compliance alone with current EU legislation for particulate matter and ozone, in short, does not adequately protect public health.

2) Outdoor air pollution is one of the biggest environmental health threats in Europe today, leading to significant reductions of life expectancy and productivity.

A few years ago, the WHO estimated the effects of man-made airborne particulate matter on life expectancy [2]. The results of this analysis indicate that current exposure to particulate matter from anthropogenic sources leads to an average loss of 8.6 months of life expectancy in Europe. The impacts vary from around 3 months in Finland to more than 13 months in Belgium.

Impacts on productivity (measured as days lost from work) could be substantial as well, although fewer studies exist on which estimates can be based. A recent analysis from the USA attributed 18,000,000 lost work days annually to PM2.5 exposure, and 11,000,000 school absence days to ozone exposure [3]. A European analysis calculated for the year 2005 that some 625 million restricted activity days could be attributed to ozone and PM10 alone [4].

A recent study in six western European countries compared the public health impact of nine major environmental exposures and showed that particulate air pollution clearly caused the greatest burden of disease of the nine factors investigated [5].

3) Fine particles and ozone are the most serious pollutants. There is an urgent need to reduce their concentrations significantly.

Numerous studies have documented adverse effects of fine airborne particles on public health. Cohort studies, in which large groups of people have been followed for many years, offer the strongest evidence. The most recent update of the American Cancer Society (ACS) study estimated that mortality increases by $6-8 \%$ for every $10 \mu \mathrm{g} \cdot \mathrm{m}^{-3}$ increase in long-term PM2.5 concentrations in the community [6]. Larger per cent increases were reported for cardiovascular disease and lung cancer mortality. Health impact assessments for fine particles in Europe have assumed a 6\% increase in mortality based on earlier ACS reports [7] so these estimates may have been somewhat conservative. The one European cohort study that has reported estimates for PM2.5 found a $6 \%$ increase per $10 \mu \mathrm{g} \cdot \mathrm{m}^{-3}$ as well [8]. 
Particulate matter and ozone have significant short-term effects on mortality and hospital admissions; in addition, there is now also some evidence for a long-term effect of ozone on respiratory, but not cardiovascular, mortality after adjustment for PM2.5 [9]. The impact of ozone on public health may therefore be larger than estimated in the WHO air quality guidelines. A recent analysis from the USA estimated that, annually, 130,000 premature deaths could be attributed to PM2.5, and an additional 23,700 to ozone [3], assuming the long-term effects of ozone on respiratory mortality are real.

It is generally recognised that effects of ozone and fine particles have a very low threshold, if indeed there is one. This means that exposure to levels even below the WHO air quality guidelines can still be expected to produce sizeable adverse effects on public health. Reductions of air pollution over the past two decades have been shown to be associated with increases in life expectancy in the USA and improved respiratory health [10,11].

4) Roadside pollution poses serious health threats that cannot be adequately addressed by regulating fine particle mass or ozone. Other metrics such as ultrafine particles and black carbon need to be considered in future research and so inform further regulation.

Many studies, especially from Europe, have documented adverse health effects of living or attending school close to busy roads. These effects include mortality, respiratory and cardiovascular disease in adults, as well as asthma and other respiratory and allergic reactions among children. Yet, gradients of particle mass close to busy roads are often small, and ozone concentrations are, if anything, lower close to busy roads than at some distance. It is unlikely that the observed effects can be attributed to particle mass, and certainly not to ozone. Some other pollutants have much steeper gradients close to roadways; these include ultrafine particles and black carbon (soot). Black carbon and close surrogates thereof have been used in many studies and the evidence is compelling enough to recommend consideration of black carbon as an additional health relevant indicator of air pollution for research, as well as regulation [12]. Ultrafine particles, i.e. particles below $100 \mathrm{~nm}$ in size, are increasingly being studied, and are also present in very high levels near busy roads. The evidence is not yet sufficiently strong to recommend establishing numerical air quality guidelines or limit values for ultrafine particles [13, 14], but it is prudent to strengthen policies in order to reduce or eliminate ultrafine particle emissions from motor vehicles, given the emerging toxicological and epidemiological evidence.

5) Non-tailpipe emissions (from brakes, tyres and road surfaces, etc.) pose a health threat for road users and subjects living close to busy roads.

In recent years, it has become clear that non-tailpipe emissions from brakes, tyres and road surfaces, etc. contribute significantly to fine and, in particular, coarse particles measured at roadside. This is especially so in northern countries where, in winter, roads are frequently sanded and studded tyres are used to improve traction on slippery roads. However, this is also true, albeit to a somewhat lesser extent, of parts of Europe with milder winters [15]. The risks of exposure to these particles are not yet completely understood, but toxicology studies support that these particles may have important biological effects [16, 17]. Evidence is emerging that coarse particles and wind-blown dust from, for example, the Sahara, may have adverse health effects as well, which require attention and control [18].

6) Real-world emissions of nitrogen dioxide from modern diesel engines are much higher than anticipated. This may expose many road users, and subjects living on busy roads, to short-term peak concentrations during rush hours and periods of stagnating weather that may impact on health, although to what extent requires further research.

Unexpectedly, roadside $\mathrm{NO}_{2}$ concentrations have been increasing in many areas, as a consequence of altered $\mathrm{NO}_{2} / \mathrm{NO}_{\mathrm{x}}$ ratios in emissions of diesel engines equipped with particle traps [19]. Sometimes, short-term peak concentrations reach hundreds of microgrammes per cubic metre, levels which may produce acute respiratory effects in susceptible subjects [20]. Studies have shown that the annual average limit value of $40 \mu \mathrm{g} \cdot \mathrm{m}^{-3}$ will be exceeded at many roadside locations throughout Europe for years to come [21]. The health risks associated with long-term average pollutant mixtures with such elevated $\mathrm{NO}_{2}$ concentrations require further study, as the ratio between $\mathrm{NO}_{2}$ and other components of the mixture has been changing.

7) Global warming will lead to more heatwaves, during which air pollution concentrations are also elevated and during which hot temperatures and air pollutants act in synergy to produce more serious health effects than expected from heat or pollution alone.

Higher summer temperatures and heatwaves will produce higher ozone concentrations in summer (assuming other things remain equal) [22, 23]; this will lead to increased mortality and hospital admissions. Global warming and decrease in rainfall will also increase the amount of wildfire episodes and thereby increase exposure to air pollution from biomass burning. Especially during heat waves, synergism may occur between air pollutants on the one hand and high temperatures on the other hand, producing more adverse effects on public health than would be expected from high temperatures or air pollution alone [24].

8) Combustion of biomass fuel produces toxic pollutants. This is true for controlled fires, such as in fireplaces, woodstoves and agricultural burning, as well as for uncontrolled wildfires. There is a need to assess the real health impacts of air pollution from these sources in many areas in Europe to inform on the need for better control.

The wildfire events in the summer of 2010 in Russia have dramatically illustrated how smoke from biomass combustion can lead to long periods of extremely high particulate matter air pollution concentrations [25]. The effects on mortality and morbidity are likely to have been severe but await further study. Wood smoke exposures can be high in EU areas where wood is a major source of home heating and cooking (parts of Scandinavia, the Alpine region and elsewhere) [26]. Combustion products from biomass fires are likely to be as toxic as combustion products from fossil fuels $[27,28]$, yet there is far less systematic study or control of the health effects of such pollutants. The use of biomass burning is currently been strongly promoted in Europe to reduce greenhouse gas emissions. It is important that, as much as possible, this burning should be done in larger installations with efficient and clean burning to reduce particulate air pollution emissions.

9) Compliance with current limit values for major air pollutants in Europe confers no protection for public health. In fact, very serious 
health effects occur at concentrations well below current limit values, especially those for fine particles.

The current limit values in Europe for particulate matter offer no protection whatsoever from adverse effects on public health $[1,29]$. The limit values are far above recommendations by the WHO and also well above air quality standards in the USA and other developed countries. There is an urgent need to inform national and local policy makers about this, as air pollution control policies tend to weaken once limit values are no longer exceeded, which may be legally justifiable, but offers a completely false sense of security. To some extent this is also true for ozone, where the limit values are higher than levels at which adverse effects on mortality and hospital admissions have been clearly observed [30].

10) EU policies to reduce air pollution are needed that ultimately lead to air that is clean and no longer associated with significant adverse effects on the health of European citizens. The benefits of such policies outweigh the costs by a large amount.

In view of the large negative health impacts of ambient air pollution in Europe today, urgent action is needed to reduce concentrations of especially fine particles and ozone further. Earlier cost benefit analyses have clearly shown that the monetised benefits of further pollution reduction in terms of increased life expectancy, reduced loss of productivity and reduced illness burdens outweigh the cost of further air pollution reductions [31].

Therefore, EU policies to reduce air pollution from all major sources are needed that ultimately lead to air that is clean and no longer associated with significant adverse effects on the health of the European citizens.

\section{STATEMENT OF INTEREST}

A statement of interest for B. Brunekreef can be found at www.erj. ersjournals.com/site/misc/statements.xhtml

\section{REFERENCES}

1 Brunekreef B, Maynard RL. A note on the 2008 EU standards for particulate matter. Atmos Environ 2008; 42: 6425-6430.

2 World Health Organization. Health Risks of Particulate Matter from Long-range Transboundary Air Pollution. Copenhagen, World Health Organization Regional Office for Europe, 2006. Available from www.euro.who.int/_data/assets/pdf_file/0006/ 78657/E88189.pdf.

3 Fann N, Lamson AD, Anenberg SC, et al. Estimating the national public health burden associated with exposure to ambient PM2.5 and ozone. Risk Anal 2012; 32: 81-95.

4 Nam K-M, Selin NE, Reilly JM, et al. Measuring Welfare Loss Caused by Air Pollution in Europe: a CGE Analysis. Cambridge, Massachusetts Institute of Technology Joint Program on the Science and Policy of Global Change, 2009. Available from http:// globalchange.mit.edu/files/document/MITJPSPGC_Rpt178.pdf.

5 Hänninen O, Knol A, eds. European Perspectives on Environmental Burden of Disease: Estimates for Nine Stressors in Six European Countries. Helsinki, National Institute for Health and Welfare, 2011. Available from www.thl.fi/thl-client/pdfs/b75f6999e7c4-4550-a939-3bccb19e41c1.

6 Krewski D, Jerrett M, Burnett RT, et al. Extended follow-up and spatial analysis of the American Cancer Society study linking particulate air pollution and mortality. Res Rep Health Eff Inst 2009; 5-114.
7 Pope CA 3rd, Burnett RT, Thun MJ, et al. Lung cancer, cardiopulmonary mortality, and long-term exposure to fine particulate air pollution. JAMA 2002; 287: 1132-1141.

8 Beelen R, Hoek G, van den Brandt PA, et al. Long-term effects of traffic-related air pollution on mortality in a Dutch cohort (NLCSAIR study). Environ Health Perspect 2008; 116: 196-202.

9 Jerrett M, Burnett RT, Pope CA 3rd, et al. Long-term ozone exposure and mortality. N Engl J Med 2009; 360: 1085-1095.

10 Pope CA 3rd, Ezzati M, Dockery DW. Fine-particulate air pollution and life expectancy in the United States. $N$ Engl J Med 2009; 360: 376-386.

11 Schindler C, Keidel D, Gerbase MW, et al. Improvements in PM10 exposure and reduced rates of respiratory symptoms in a cohort of Swiss adults (SAPALDIA). Am I Respir Crit Care Med 2009; 1797: 579-587.

12 Janssen NA, Hoek G, Simic-Lawson M, et al. Black carbon as an additional indicator of the adverse health effects of airborne particles compared with PM10 and PM2.5. Environ Health Perspect 2011; 119: 1691-1699.

13 Hoek G, Boogaard H, Knol A, et al. Concentration response functions for ultrafine particles and all-cause mortality and hospital admissions: results of a European expert panel elicitation. Environ Sci Technol 2010; 44: 476-482.

$14 \mathrm{Knol} \mathrm{AB}$, de Hartog JJ, Boogaard $\mathrm{H}$, et al. Expert elicitation on ultrafine particles: likelihood of health effects and causal pathways. Part Fibre Toxicol 2009; 6: 19.

15 Hussein T, Johansson C, Karlsson H, et al. Factors affecting nontailpipe aerosol particle emissions from paved roads: on-road measurements in Stockholm, Sweden. Atmos Environ 2008; 42: 688-702.

16 Gerlofs-Nijland ME, Dormans JAMA, Bloemen HJT, et al. Toxicity of coarse and fine particulate matter from sites with contrasting traffic profiles. Inhal Toxicol 2007; 19: 1055-1069.

17 Boogaard H, Janssen NA, Fischer PH, et al. Contrasts in oxidative potential and other PM characteristics collected near major streets and background locations. Environ Health Perspect 2011 [Epub ahead of print DOI: 10.1289/ehp.1103667].

18 Mallone S, Stafoggia M, Faustini A, et al. Saharan dust and associations between particulate matter and daily mortality in Rome, Italy. Environ Health Perspect 2011; 119: 1409-1414.

19 Carslaw D, Beevers S, Westmoreland E, et al. Trends in $\mathrm{NO}_{x}$ and $\mathrm{NO}_{2}$ Emissions and Ambient Measurements in the UK (draft version, March 3, 2011). Department for the Environment, Farming and Rural Affairs (UK), 2011. Available from www. accent-network.org/accent_documents/Draft_NOx_NO2_trends_ report.pdf.

20 US Environmental Protection Agency. Integrated Science Assessment for Oxides of Nitrogen - Health Criteria (Final Report). Washington, US EPA, 2008. Available from http://cfpub.epa.gov/ ncea/cfm/recordisplay.cfm?deid $=194645$.

21 Guerreiro C, Larssen S, de Leeuw F, et al. Air Quality in Europe. Copenhagen, European Environment Agency, 2011. Available from www.eea.europa.eu/publications/air-quality-in-europe-2011.

22 Tagaris E, Liao KJ, Delucia AJ, et al. Potential impact of climate change on air pollution-related human health effects. Environ Sci Technol 2009; 43: 4979-4988.

23 Ayres JG, Forsberg B, Annesi-Maesano I, et al. Climate change and respiratory disease: European Respiratory Society position statement. Eur Respir J 2009; 34: 295-302.

24 Pattenden S, Armstrong B, Milojevic A, et al. Ozone, heat and mortality: acute effects in 15 British conurbations. Occup Environ Med 2010; 67: 699-707.

25 van Donkelaar A, Martin RV, Levy RC, et al. Satellite-based estimates of ground-level fine particulate matter during extreme events: a case study of the Moscow fires in 2010. Atmos Environ 2011; 45: 6225-6232. 
26 Bari MA, Baumbach G, Kuch B, et al. Temporal variation and impact of wood smoke pollution on a residential area in southern Germany. Atmos Environ 2010; 44: 3823-3832.

27 Barregard L, Saellsten G, Andersson L, et al. Experimental exposure to wood smoke: effects on airway inflammation and oxidative stress. Occup Environ Med 2008; 65: 319-324.

28 Mazzoli-Rocha F, Magalhaes CB, Malm O, et al. Comparative respiratory toxicity of particles produced by traffic and sugar cane burning. Environ Res 2008; 108: 35-41.
29 Annesi-Maesano I, Forastiere F, Kunzli N, et al. Particulate matter, science and EU policy. Eur Respir J 2007; 29: 428-431.

30 Bell ML, Dominici F, Samet JM. A meta-analysis of time-series studies of ozone and mortality with comparison to the national morbidity, mortality, and air pollution study. Epidemiology 2005; 16: 436-445.

31 Holland M, Pye S. An Update on Cost-benefit Analysis for the CAFE Programme. Didcot, AEA Technology Environment, 2006. Available from http://ec.europa.eu/environment/archives/cafe/ pdf/cba_update_nov2006.pdf. 